\title{
UNA INTERPRETACIÓN APROXIMATIVA A LOS MATERIALES PARA LA REFORMA DE LA LEGISLACIÓN CONCURSAL, ISABEL CANDELARIO MACÍAS
}

\author{
Sergio Peña Neira
}

Isabel Candelario Macías. "Una interpretación aproximativa a los materiales para la reforma de la legislación concursal" ( Suplemento al № 1768 de 15 de febrero de 1996). Boletín de información del Ministerio de Justicia) en II Diritto falliementari e delle societá comercialli, Amata LXXXII a, Gennaio-Febraio 1997 N.1. Cedam-Casa Editrice Dott. Antonio Milani-Padova.

El trabajo aquí presentado posee la rigurosidad y profundidad suficiente alcanzada por quien ha dedicado largo tiempo a la investigación y meditación en un tema tan importante como los procedimientos concursales y de tantos "dolores de cabeza" para la economía de un país. En efecto, el material presentado por la autora del texto, es la propuesta legal elaborada por el catedrático Dr. Ángel Rojo para España. Este anteproyecto busca modificar el procedimiento que actualmente rige el tema en la Madre Patria. Además, el texto en comento es un paso dentro del largo proceso de investigación llevado adelante por la autora en el marco de sus estudios de doctorado y no dudamos será tan completa como el texto reseñado.

La insolvencia, como muchas instituciones en el Derecho, es objeto de al menos dos disciplinas jurídicas, a saber, el Derecho comercial ${ }^{1}$ y el Derecho procesal ${ }^{2}$

Sin perjuicio de ser reclamada por el Derecho penal ${ }^{3}$. La interpretación aproximativa de los materiales para la reforma de la legislación concursal es visto desde las dos primeras perspectivas apuntadas. Ella, como lo indica el editor en la página 123 es una contribución "al grandi movimenti legislativi dei Paesi della Comunitá europea, in unitá de fini nella reforma delle leggi relativa al diritto commercialle e fallimentari".

La autora muestra un indudable interés en la conservación de la empresa como medio de protección del crédito en los procedimientos concursales. Lo anterior consecuencia o producto de haber escogido para su tesis doctoral el tal tema por poseer este tema ingredientes importantes de incidencia en la economía y en el empleo de un país. Además, dado el que existe una interrelación muy fuerte entre los países europeos producto de la comunidad formada entre ellos es de suyo importante buscar mantener las

${ }^{1}$ En materia comercial puede verse como ejemplo Ricardo Sandoval, Derecho comercial, Editorial jurídica de Chile, 4a Edición, T III, 1995, p. 7 ss.

Al respecto apuntamos al Catedrático de la Universidad de Valparaíso, Chile, Manuel de Rivacoba, Programa Analítico de Derecho penal (puesto al día por el Profesor de la Universidad de Antofagasta y de la Universidad Católica del Norte Dr. José Luis Guzmán Dálbora), Editorial Edeval, Valparaíso, 1997. Dicho sea de paso, es el texto más completo escrito en Chile acerca de lo que debe ser un programa de Derecho penal. 
empresas en funcionamiento evitando migraciones no esperadas y posibles de desbalancear a un país.

A fin de evitar la quiebra se establece una fórmula intermedia entre la simple quiebra y el pago de los créditos consistente en una suspensión de pagos (p.125). Luego, el concurso se convierte en el actor principal para alcanzar el término de la empresa.

El objetivo de este proyecto es aplicar a la legislación concursal las concepciones modernas sobre el tema. Así se logra satisfacer a los acreedores ofreciendo, previo a la satisfacción compulsiva, convenios de continuación de la empresa unido a las debidas garantías. Un segundo objetivo a alcanzar con el proyecto en cuestión, es el de la unidad legal como de disciplina a fin de alcanzar equilibrio entre continuidad y término de la empresa. Se supera con ello las dualidades procedimentales. Se admite la suspensión de pagos respecto de quien no ha cumplido con las obligaciones contraídas sin ser de carácter significativo dicha falta de cumplimiento.

La autora no deja de establecer algunas críticas al proyecto. éste abandona formas de dar solución a la cesación de pagos y que se contemplan en la legislación vigente ${ }^{4}$ para la celebración del convenio (p.126-127). Así también critica a la denominación del proyecto, "Ley concursal" por no proporcionar una idea cabal acerca de las diferentes alternativas frente a la cesación de pagos por el empresariado.

El convenio como medio de posibilitar la conservación de la empresa es estudiado en sus antecedentes ( $p .132$ ), naturaleza jurídica (p.133) dándole el carácter de pacto entre deudor con la mayoría de sus acreedores para solucionar el pago de sus créditos dentro del procedimiento concursal ( p. 135). Posteriormente estudia la tipología anterior a la declaración de quiebra (p. 135). Estos convenios pueden tener por finalidad:

a) Ceder bienes en beneficio de los acreedores.

b) Obtener un compromiso a través del cual con el pago de una parte de la deuda se entiende cumplida el total.

c) Lograr un acuerdo por el cual se confiere a los acreedores la posibilidad de continuar o liquidar el negocio del deudor (p.136).

En cuanto a las conclusiones la profesora Candelario señala la posibilidad contemplada en el proyecto para la continuación de la empresa si ella es viable. Esta propuesta, indica la autora, tiene el mérito de dar especial relevancia a soluciones contractuales donde prima la autonomía de la voluntad de los agentes económicos evitando con ello la intervención del estado en la materia y manteniendo el esquema de una economía de mercado (p.145).

En síntesis, calidad y profundidad califican al texto que hemos comentado en estas líneas. Augura ello, un trabajo investigativo y docente de calidad.

\footnotetext{
${ }^{4}$ En nota que nos ha hecho llegar la autora se nos ha señalado la vigencia de la antigua normativa y la improbable vigencia de este texto.
} 